\title{
MRI sagittal abdominal diameter is a stronger predictor of metabolic syndrome than visceral fat area or waist circumference in a high-risk vascular cohort
}

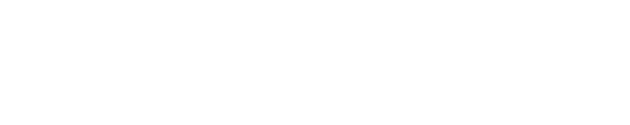

\section{Michel R Hoenig}

University of Queensland, Brisbane, Queensland, Australia
Correspondence: Michel R Hoenig University of Queensland, Centre for Clinical Research, Building 7I, Royal Brisbane and Women's Hospital, Herston QId 4029, Australia

Tel +6I 6036677950

Fax +61733465599

Emaildrmhoenig@yahoo.com.au
Objective: To determine whether sagittal abdominal diameter (SAD) is associated with the metabolic syndrome independently of visceral fat area (VFA) and waist circumference (WC). Methods: Forty-three high-risk vascular patients were evaluated for metabolic syndrome criteria and underwent magnetic resonance imaging (MRI) to quantify SAD and VFA at the L4-L5 disc.

Comparisons: 1 . Baseline differences in patients with and without the metabolic syndrome 2. Forward binary logistic regression analysis of predictors of the metabolic syndrome with SAD, VFA and WC as independents 3. Correlates of SAD.

Results: Patients with metabolic syndrome had greater SAD, VFA and WC than patients without the metabolic syndrome $(P<0.01)$. Of SAD, VFA and WC, only SAD was associated with metabolic syndrome on forward binary logistic regression; beta 0.68 , Wald's statistic 10.8 $(P=0.001)$ and c-statistic $0.89(P<0.001)$. A $>22.7 \mathrm{~cm} \mathrm{SAD} \mathrm{threshold} \mathrm{identified} \mathrm{metabolic}$ syndrome with a $91 \%$ sensitivity and $80 \%$ specificity. SAD correlated with waist circumference $(r=0.918)$, high-density lipoprotein-cholesterol $(r=-0.363)$, triglyceride $(r=0.401)$, fasting glucose $(\mathrm{r}=0.428)$ and the QUICK index of insulin sensitivity $(\mathrm{r}=-0.667)($ all $P<0.05)$.

Conclusions: MRI-measured SAD is associated with the metabolic syndrome and renders the current gold standard of VFA redundant. This measure of obesity-related cardiovascular risk requires validation and evaluation in a prospective cohort.

Keywords: obesity, insulin resistance, waist circumference, metabolic syndrome, sagittal abdominal diameter, visceral fat area

\section{Introduction}

The increased risk of cardiovascular events associated with obesity is driven by the accumulation of visceral fat and insulin resistance. ${ }^{1-5}$ Waist circumference (WC) is typically used in clinical practice to both quantify abdominal obesity and to make the diagnosis of the metabolic syndrome. In patients with established vascular disease, as in healthy patients, the diagnostic label of 'metabolic syndrome' portends an increased risk of cardiovascular events and therefore carries clinical significance. ${ }^{6-9}$ While several reports have suggested that the anteroposterior diameter of the abdomen, the sagittal abdominal diameter (SAD), is a superior correlate of metabolic syndrome criteria and insulin resistance than waist circumference, there has been little incorporation of this measure into routine clinical practice. ${ }^{10-13} \mathrm{SAD}$ has recently been suggested to be a superior predictor of the metabolic syndrome than visceral fat area (VFA) in a single report. ${ }^{14}$ VFA, measured at the umbilicus, is the current gold standard for the 
determination of obesity-related cardiovascular risk and is a determinant of metabolic risk factors and the metabolic syndrome after correction for body mass index (BMI) and WC. ${ }^{4,15}$ Further, VFA has been independently linked to the development of coronary artery disease. ${ }^{16}$ Hence, the finding that SAD is a superior predictor of the metabolic syndrome than VFA potentially carries important implications. Firstly, SAD may be measured with the Holtain-Kahn abdominal caliper without requiring any imaging, with its associated costs. Secondly, while commercial software is available to automate the process of quantifying fat areas from imaging, the process remains time-consuming and requires human input for analysis of appropriate images. Hence we sought to reproduce the finding that SAD is a superior predictor of the metabolic syndrome than VFA and to also compare this to WC. Further, we sought to investigate the correlation of SAD with the individual criteria of the metabolic syndrome and insulin sensitivity on a continuous scale.

\section{Methods}

\section{Study population}

We recruited patients with coronary artery disease (CAD), ischemic stroke, or CAD risk-equivalents. Eligible patients had to have at least one of the following: 1. CAD (positive angiogram or history of myocardial infarction) 2. Peripheral vascular disease $(\mathrm{ABI}<0.9$ or history of lower limb revascularization for atherosclerosis) 3. Abdominal aortic aneurysm 4 . carotid atherosclerosis with $>50 \%$ narrowing 5. type II diabetes with age $>50$ and 3 additional risk factors (male sex, albuminuria, hypertension, high-density lipoprotein-cholesterol [HDL-C] $<40 \mathrm{mg} / \mathrm{dL}$, triglycerides [TG] $>150 \mathrm{mg} / \mathrm{dL}$, low-density lipoprotein-cholesterol [LDL-C] $>100 \mathrm{mg} / \mathrm{dL}$, current smoking, diabetes duration $>20$ years), or 6 . Ischemic stroke. Eligible patients were not taking lipid-modifying drugs. Study participants were in a clinically stable condition and were recruited from the vascular surgery outpatient department at the Royal Brisbane and Women's Hospital.

\section{Patient data}

Patient demographic information was collected including age, sex, qualifying criterion, self-reported race, current medications, cigarette smoking, blood pressure, anti-hypertensive medication use, height, weight, and waist circumference. Metabolic syndrome was defined as per the Adult Treatment Panel III (ATP III) criteria. ${ }^{17}$ Fasting blood samples were analyzed for baseline lipids, glucose, and insulin. Fasting lipid profile and glucose were determined using standard hospital methods. Insulins were measured by chemilumnescent immunoassay on a Beckman Coulter DxI800 (Beckman Coulter UK Ltd, London, UK) as per the manufacturer's instructions. To determine insulin sensitivity, we used the quantitative insulin sensitivity check index (QUICK index) since this a superior linear correlate $(r \sim 0.8-0.9)$ of the reference standard glucose clamp than the homeostasis model assessment (HOMA) model. ${ }^{18,19}$

\section{MRI measurement of abdominal fat areas}

MR imaging was performed with a Siemens Trio $3 \mathrm{~T}$ MRI system (Siemens AG, Erlangen, Germany) using standard array coils with the subject supine. Breath-hold FISP images were centered on the L4-L5 intervertebral disc using standard localizer images with the following parameters: $\mathrm{TR}=4 \mathrm{~ms}$, $\mathrm{TE}=2 \mathrm{~ms}$, number of slices $=12$, slice thickness $=8 \mathrm{~mm}$, image matrix $256 \times 256$, field-of-view $=500 \times 500 \mathrm{~mm}$. The 4 slices that were best aligned with the L4-L5 disc $(19,20)$, were analyzed using the polygon region of interest in Escape medical viewer v3.2 to define visceral fat area (VFA) as described previously. ${ }^{20}$ Briefly, VFA was measured by fitting a spline curve to points on the border of the subcutaneous and visceral regions. Nonfat regions within the visceral region were also outlined with a spline fit and subtracted from the total visceral region. The SAD was measured at the L4-L5 disc by measuring the distance from the anterior part of the body to the posterior portion of the body using the caliper function on the software package. However, SAD can be measured using the Holtain-Kahn abdominal caliper without imaging.

\section{Statistical methods}

The baseline characteristics of the included patients were summarized and the diagnosis of the metabolic syndrome as per ATP III criteria ${ }^{17}$ was determined for each patient. We compared patients with and without the metabolic syndrome for various metabolic parameters and imaging parameters. We compared the means of continuous variables with a two-tailed Student's $t$-test for normally distributed variables, and with the Mann-Whitney $U$ test for non-normally distributed variables. Categorical variables were analyzed with the Chi-square test or Fisher's exact test. We then used forward LR binary logistic regression to identify independent predictors of patients having the diagnosis of the metabolic syndrome. Candidate variables selected for logistic regression were three measures of obesity: VFA, SAD, and WC. Variables were only entered into the model if the $P$-value of the score statistic was less than the entry value of 0.05 . Wald statistics and odds ratios were reported for 
variables in the final model and the overall model was assessed with the c-statistic for predicting the metabolic syndrome. ROC curves were used to identify an optimal SAD cut-off for predicting the metabolic syndrome with acceptable sensitivity and specificity. In order to determine correlates of SAD, we undertook univariate correlation with the metabolic syndrome criteria and insulin sensitivity (the QUICK index) as independents and SAD as the dependent variable. The QUICK index of insulin sensitivity for each subject with insulin and glucose data was calculated as $1 /[\log$ (fasting insulin, $\mu \mathrm{U} / \mathrm{mL}$ ) $+\log$ (fasting glucose, mg/dL)]. ${ }^{18}$ Variables that correlated with SAD with a Spearman's $P<0.05$ were subjected to stepwise multivariate linear regression and the $\mathrm{R} 2$ change calculated with the addition of any variable to the model. To remove the influence of multicollinearity from the multiple regression model, variance-inflation factors (VIFs) were determined, and variables with a VIF $>4.0$ were removed from the model. Residuals from the regression model were graphically examined. All analyses were done with statistics software (V. 16 SPSS Inc., Chicago, IL, USA).

\section{Ethics approval}

This study is approved by the RBWH research ethics committee (2005/006A) and all study participants gave informed consent.

\section{Results}

We enrolled 43 patients in this MRI study. Baseline characteristics, including components of the metabolic syndrome, baseline lipid panel, insulin and QUICK index of insulin sensitivity are shown in Table 1. The differences between the patients with and without the metabolic syndrome are summarized in Table 2 and show expected differences in various metabolic parameters. Patients with metabolic syndrome had greater WC, SAD, and VFA compared to patients without the metabolic syndrome $(P<0.01)$. In order to determine which of these measures of obesity is most strongly associated with the metabolic syndrome, we subjected the outcome of metabolic syndrome to binary logistic regression analysis with WC, SAD, and VFA as independents. On forward logistic regression, only SAD entered the model with no independent contribution from waist circumference or VFA; beta 0.68 , Wald's statistic $10.8, P=0.001$. The overall c-statistic for SAD in identifying the metabolic syndrome was 0.89 $(P<0.001)$ and, in this sample, an SAD of $>22.7 \mathrm{~cm}$ identified the metabolic syndrome with $91 \%$ sensitivity and $80 \%$ specificity.
Table I Characteristics of patients included in the analysis

\begin{tabular}{|c|c|}
\hline & Mean \pm SD or $n(\%)$ \\
\hline Age & $70 \pm 8$ \\
\hline Males & $35(8 I)$ \\
\hline Females & $8(19)$ \\
\hline \multicolumn{2}{|l|}{ Race } \\
\hline White & $42(98)$ \\
\hline Non-White & I (2) \\
\hline Height (cm) & $172 \pm 10$ \\
\hline Weight (kg) & $79 \pm 19$ \\
\hline Body mass index & $26 \pm 5$ \\
\hline Diabetic, n (\%) & $10(23)$ \\
\hline Metabolic syndrome (ATP III), n (\%) & $22(53)$ \\
\hline Waist $(\mathrm{cm})$ & $101 \pm 16$ \\
\hline Visceral fat area $\left(\mathrm{cm}^{2}\right)$ & $203 \pm 111$ \\
\hline Sagittal abdominal diameter $(\mathrm{cm})$ & $23.2 \pm 4.0$ \\
\hline Fasting glucose (mg/dl) & $112 \pm 40$ \\
\hline HDL cholesterol (mg/dl) & $44 \pm 17$ \\
\hline Triglycerides (mg/dl) & $142 \pm 74$ \\
\hline Systolic blood pressure $(\mathrm{mmHg})$ & $142 \pm 19$ \\
\hline Diastolic blood pressure $(\mathrm{mmH})$ & $72 \pm 9$ \\
\hline Average number of ATP III criteria & $2.7 \pm 1.5$ \\
\hline Fasting insulin (mU/L) & $7 \pm 4$ \\
\hline QUICK index & $0.25 \pm 0.03$ \\
\hline \multicolumn{2}{|l|}{ Qualifying criterion ${ }^{\mathrm{a}}$} \\
\hline Coronary artery disease & $10(24)$ \\
\hline Peripheral vascular disease & $23(55)$ \\
\hline Carotid atherosclerosis $>50 \%$ & $12(29)$ \\
\hline Abdominal aortic aneurysm & $10(24)$ \\
\hline Ischemic stroke & $8(19)$ \\
\hline Diabetes & $10(24)$ \\
\hline
\end{tabular}

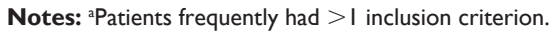

Abbreviations: ATP, Adult Treatment Panel; HDL, high-density lipoprotein; SD, standard deivation.

Despite the criticism of the label of metabolic syndrome as being no greater than a sum of risk factors, it remains a clinically-useful label denoting an increased cardiovascular risk. ${ }^{21}$ However, given evidence that insulin resistance drives the increased risk of cardiovascular events in obese individuals, ${ }^{22}$ we assessed the utility of an SAD of $>22.7 \mathrm{~cm}$ in identifying insulin-resistant patients. We compared the QUICK index of insulin sensitivity in patients with an SAD of $>22.7 \mathrm{~cm}$ and $<22.7 \mathrm{~cm}$ and found that patients with $\mathrm{SAD}>22.7 \mathrm{~cm}$ were significantly more insulin resistant (lower QUICK index score) than those with an $\mathrm{SAD}<22.7 \mathrm{~cm}, P=0.01$. Next, we sought to confirm the association between SAD and metabolic indicators of risk by correlating the SAD to each of the metabolic syndrome criteria and the QUICK index. The QUICK index and all the metabolic syndrome criteria, except for the hypertension criterion, were significant correlates of SAD as shown in Table 3. On stepwise multivariate analysis of the significant univariate correlates as independents and SAD as the 
Table 2 Characteristics of the patients with and without the metabolic syndrome (Met Syn)

\begin{tabular}{|c|c|c|c|}
\hline \multirow[t]{2}{*}{ Variable } & \multicolumn{2}{|c|}{ Mean \pm SD or $n(\%)$ of patients } & \multirow[t]{2}{*}{$P$ value MetSyn vs without MetSyn } \\
\hline & With MetSyn $(n=23)$ & Without MetSyn $(n=20)$ & \\
\hline Waist (cm) & $110 \pm 10$ & $91 \pm 15$ & $<0.001$ \\
\hline Sagittal abdominal diameter $(\mathrm{cm})$ & $25.6 \pm 3.3$ & $20.4 \pm 2.6$ & $<0.001$ \\
\hline Visceral fat area $\left(\mathrm{cm}^{2}\right)$ & $263 \pm 113$ & $134 \pm 53$ & $<0.001$ \\
\hline Number of ATP III criteria & $3.9 \pm 0.7$ & $1.3 \pm 0.7$ & $<0.001$ \\
\hline $\mathrm{HDL}-\mathrm{C}(\mathrm{mg} / \mathrm{dL})$ & $39 \pm 18$ & $50 \pm 15$ & 0.007 \\
\hline $\mathrm{TG}(\mathrm{mg} / \mathrm{dL})$ & $|77 \pm 8|$ & $102 \pm 38$ & $<0.001$ \\
\hline Fasting glucose $(\mathrm{mg} / \mathrm{dL})$ & $127 \pm 50$ & $96 \pm 8$ & 0.001 \\
\hline Hypertension, n (\%) & $17(74)$ & $10(50)$ & 0.065 \\
\hline Diabetic, n (\%) & $10(43)$ & $0(0)$ & 0.001 \\
\hline Male, n (\%) & $19(83)$ & $16(80)$ & 0.83 \\
\hline Age & $69 \pm 7$ & $69 \pm 10$ & 0.75 \\
\hline Fasting insulin (mU/L) & $9.3 \pm 4.9$ & $4.9 \pm 2.7$ & 0.001 \\
\hline QUICK index of insulin sensitivity & $0.242 \pm 0.031$ & $0.263 \pm 0.26$ & 0.001 \\
\hline
\end{tabular}

Abbreviations: ATP, Adult Treatment Panel; HDL-C, high-density lipoprotein cholesterol; SD, standard deviation; TG, triglycerides.

dependent variable, only waist circumference is retained in the model with an R2 of $0.79, P<0.001$. Hence, waist circumference is an important determinant of SAD but does not explain all the variation in SAD.

\section{Discussion}

This report is the second report to show that $\mathrm{SAD}$ is a stronger predictor of the metabolic syndrome than the current gold standard for assessing obesity-related cardiovascular risk, the VFA. Unlike VFA, SAD does not require imaging to be measured. An SAD value of $>22.7 \mathrm{~cm}$ identified patients with the metabolic syndrome with a $91 \%$ sensitivity and $80 \%$ specificity. Patients with an SAD $>22.7 \mathrm{~cm}$ had significantly lower QUICK insulin sensitivity indices than patients with an $\mathrm{SAD}<22.7 \mathrm{~cm}$ which is consistent with this threshold being able to identify insulin-resistant patients. SAD correlates with insulin sensitivity and all components of the metabolic syndrome except for hypertension. On multivariate regression, waist circumference is the only significant determinant of SAD (R2 of $0.79, P<0.001$ ).

The association of SAD with the metabolic syndrome is a clinically-significant one since the clinical label of 'metabolic syndrome' in patients with established vascular disease identifies a cohort at an increased risk of cardiovascular events. ${ }^{6-9}$ Hence, this measure of obesity can potentially identify a higher-risk cohort. While our data are encouraging in showing that SAD may better identify the higher-risk patient than VFA, our data set is small and cross-sectional. A large prospective cohort is required to determine if $\mathrm{SAD}$ is independently associated with cardiovascular events. From a pragmatic perspective, such a measure would be preferable to VFA for quantifying obesity-related cardiovascular risk since SAD can theoretically be measured in the office without requiring an imaging modality. However, clinic measurements of SAD using Holtain-Kahn calipers typically result in larger values than the MRI-measured SAD and would therefore require independent validation and adjustment for a predictive cut-off value. Nevertheless, the conclusions reached from the MRI-derived SAD cannot be extended to caliperderived measurements without validation. In summary, we have shown MRI-measured SAD to be associated with the metabolic syndrome independently of VFA. SAD requires further validation as a maker of obesity-related cardiovascular risk and assessment in prospective cohort studies. This measure could potentially replace waist circumference as the preferred office-based method of assessing obesityrelated cardiovascular risk.

Table 3 Univariate correlates of sagittal abdominal diameter

\begin{tabular}{lllllll}
\hline & $\begin{array}{l}\text { Waist } \\
\text { circumference }\end{array}$ & $\begin{array}{l}\text { HDL } \\
\text { cholesterol }\end{array}$ & $\begin{array}{l}\text { Fasting } \\
\text { triglyceride }\end{array}$ & Fasting glucose & $\begin{array}{l}\text { ATP III hypertension } \\
\text { criterion }\end{array}$ & $\begin{array}{l}\text { QUICK } \\
\text { index }\end{array}$ \\
\hline Spearman's coefficient & 0.918 & -0.363 & 0.401 & 0.428 & 0.198 & -0.667 \\
$P$ value & $<0.001$ & 0.017 & 0.008 & 0.004 & 0.204 & $<0.001$ \\
\hline
\end{tabular}

Abbreviations: ATP, Adult Treatment Panel; HDL, high-density lipoprotein. 


\section{Acknowledgments}

This work is supported by Pfizer Australia AUS-ATO-06002 (MRH) and the Royal Brisbane and Women's Hospital Foundation (MRH). MRH receives salary support from the National Health and Medical Research Council of Australia (\#409936). MRH thanks all the vascular surgery staff at the Royal Brisbane and Women's Hospital for their assistance in identifying eligible patients. MRH thanks Dr Gary Cowin (Center for Magnetic Resonance, University of Queensland) and the staff at the Department of Radiology, Royal Brisbane and Women's Hospital, for their assistance in image acquisition. The author declares no conflict of interest.

\section{References}

1. Grundy SM. Metabolic syndrome: connecting and reconciling cardiovascular and diabetes worlds. J Am Coll Cardiol. 2006;47:1093-1100.

2. Zimmet P, Magliano D, Matsuzawa Y, Alberti G, Shaw J. The metabolic syndrome: a global public health problem and a new definition. J Atheroscler Thromb. 2005;12:295-300.

3. Bonora E. The metabolic syndrome and cardiovascular disease. Ann Med. 2006;38:64-80.

4. Carr DB, Utzschneider KM, Hull RL, et al. Intra-abdominal fat is a major determinant of the National Cholesterol Education Program Adult Treatment Panel III criteria for the metabolic syndrome. Diabetes. 2004;53:2087-2094

5. Grundy SM, Cleeman JI, Daniels SR, et al. Diagnosis and management of the metabolic syndrome: an American Heart Association/National Heart, Lung, and Blood Institute Scientific Statement. Circulation. 2005; 112:2735-2752.

6. Vlek AL, van der Graaf Y, Spiering W, Visseren FL. Effect of metabolic syndrome or type II diabetes mellitus on the occurrence of recurrent vascular events in hypertensive patients. J Hum Hypertens. 2008;22:358-365.

7. Vlek AL, van der Graaf Y, Sluman MA, Moll FL, Visseren FL, Group SS. Metabolic syndrome and vascular risk in patients with peripheral arterial occlusive disease. J Vasc Surg. 2009;50:61-69.

8. Wassink AM, van der GraafY, Soedamah-Muthu SS, Spiering W, Visseren FLj; Smart Study Group. Metabolic syndrome and incidence of type 2 diabetes in patients with manifest vascular disease. Diab Vasc Dis Res. 2008;5:114-122.

9. Brevetti G, Laurenzano E, Giugliano G, et al. Metabolic syndrome and cardiovascular risk prediction in peripheral arterial disease. Nutr Metab Cardiovasc Dis. 2009.

10. Valsamakis G, Chetty R, Anwar A, Banerjee AK, Barnett A, Kumar S. Association of simple anthropometric measures of obesity with visceral fat and the metabolic syndrome in male Caucasian and Indo-Asian subjects. Diabet Med. 2004;21:1339-1345.
11. Riserus U, Arnlov J, Brismar K, Zethelius B, Berglund L, Vessby B. Sagittal abdominal diameter is a strong anthropometric marker of insulin resistance and hyperproinsulinemia in obese men. Diab Care. 2004;27:2041-2046

12. Petersson H, Daryani A, Riserus U. Sagittal abdominal diameter as a marker of inflammation and insulin resistance among immigrant women from the Middle East and native Swedish women: a cross-sectional study. Cardiovasc Diabetol. 2007;6:10.

13. Ohrvall M, Berglund L, Vessby B. Sagittal abdominal diameter compared with other anthropometric measurements in relation to cardiovascular risk. Int J Obes Relat Metab Disord. 2000;24:497-501.

14. Valsamakis G, Jones A, Chetty R, et al. MRI total sagittal abdominal diameter as a predictor of metabolic syndrome compared to visceral fat at L4-L5 level. Curr Med Res Opin. 2008;24:1853-1860.

15. Fox CS, Massaro JM, Hoffmann U, et al. Abdominal visceral and subcutaneous adipose tissue compartments: association with metabolic risk factors in the Framingham Heart Study. Circulation. 2007; 116:39-48.

16. Fujimoto WY, Bergstrom RW, Boyko EJ, et al. Visceral adiposity and incident coronary heart disease in Japanese-American men. The 10-year follow-up results of the Seattle Japanese-American Community Diabetes Study. Diab Care. 1999;22:1808-1812.

17. Third Report of the National Cholesterol Education Program (NCEP) Expert Panel on Detection, Evaluation, and Treatment of High Blood Cholesterol in Adults (Adult Treatment Panel III) final report. Circulation. 2002;106:3143-3421.

18. Muniyappa R, Lee S, Chen H, Quon MJ. Current approaches for assessing insulin sensitivity and resistance in vivo: advantages, limitations, and appropriate usage. Am J Physiol Endocrinol Metab. 2008;294:E15-E26.

19. Sarafidis PA, Lasaridis AN, Nilsson PM, et al. Validity and reproducibility of HOMA-IR, 1/HOMA-IR, QUICKI and McAuley's indices in patients with hypertension and type II diabetes. J Hum Hypertens. 2007;21:709-716.

20. Chowdhury B, Sjöström L, Alpsten M, Kostanty J, Kvist H, Löfgren R. A multicompartment body composition technique based on computerized tomography. Int J Obes Relat Metab Disord. 1994;18: 219-234.

21. Alberti KG, Eckel RH, Grundy SM, et al. Harmonizing the metabolic syndrome: a joint interim statement of the International Diabetes Federation Task Force on Epidemiology and Prevention; National Heart, Lung, and Blood Institute; American Heart Association; World Heart Federation; International Atherosclerosis Society; and international association for the Study of Obesity. Circulation. 2009;120:1640-1645.

22. Reaven GM. Insulin resistance: the link between obesity and cardiovascular disease. Endocrinol Metab Clin North Am. 2008;37:581-601, vii-viii.
Vascular Health and Risk Management

\section{Publish your work in this journal}

Vascular Health and Risk Management is an international, peerreviewed journal of therapeutics and risk management, focusing on concise rapid reporting of clinical studies on the processes involved in the maintenance of vascular health; the monitoring, prevention and treatment of vascular disease and its sequelae; and the involvement of

\section{Dovepress}

metabolic disorders, particularly diabetes. This journal is indexed on PubMed Central and MedLine. The manuscript management system is completely online and includes a very quick and fair peer-review system, which is all easy to use. Visit http://www.dovepress.com/ testimonials.php to read real quotes from published authors. 